\title{
JURISDICCIÓN E INDEPENDENCIA JUDICIAL: EL PODER JUDICIAL COMO PODER NULO
}

\author{
1. Introducción; 2. Bocas de las leyes; 3. Justificación y aplicación; 4. El poder judicial como \\ poder nulo; 5. La expresión "Poder Judicial" como abreviatura; 6. Atención al caso e \\ independencia judicial; 7. Una objeción final y Conclusión.
}

\section{Introducción}

En este artículo quiero defender una concepción de la independencia judicial que resulta novedosa aunque en algún sentido profundo es tradicional. Para hacerlo, sin embargo, será necesario preguntarse antes por la jurisdicción y su función en un estado de derecho. A mi juicio, esta afirmación no es sólo el lugar común de que no es posible entender una parcela del mundo sin mirar a las parcelas colindantes, como el que dice que no es posible tener una comprensión cabal del fenómeno biológico sin una comprensión adecuada de los fenómenos físicos sobre los cuales se construye. En este sentido es evidente que no podemos decir algo sobre la independencia judicial sin tener una noción al menos intuitiva de la función jurisdiccional y el rol que ocupa en un estado de derecho, pero si fuera sólo esto lo que quiero decir lo mismo se aplicaría a la jurisdicción misma y al Estado de derecho: para hablar de ellos sería necesario referirse a otras cosas, y a sus parcelas colindantes, etc. Acabaríamos en una regresión al infinito que nos enmudecería.

La razón por la cual es especialmente necesario hoy en día reflexionar sobre la jurisdicción y su función como antecedente de la discusión sobre la independencia judicial es que las instituciones políticas y jurídicas en general, y la organización judicial en un estado de derecho en particular, descansan sobre principios justificadores. Esos principios definen no sólo su función y limitaciones sino también sus características y modos de actuación, de modo tal que sin esos principios esas características y modos de actuación pueden parecer arbitrarios o contraproducentes. Así, por ejemplo, Max Weber decía, refiriéndose a un caso problemático en el derecho alemán de principios de siglo, que "un 'lego' nunca podrá entender que, de acuerdo a la vieja definición del delito de robo, no pueda existir un 'robo' de energía eléctrica". Para un abogado, que entiende la importancia del principio de legalidad, esa afirmación no sólo es comprensible; el abogado entiende que hay algo extraordinariamente importante escondido detrás de la conclusión de que si la acción típica es apropiarse de cosa mueble, y si la electricidad - conforme a las convenciones

\footnotetext{
* Universidad Adolfo Ibáñez (fernando.atria@uai.cl). Este artículo es una version corregida y ampliada de la conferencia inaugural del seminario "Jueces y Estado de Derecho", organizado por el Instituto de Estudios Judiciales, la Asociación Nacional de Magistrados y el Centro de Estudios de la Justicia de la Universidad de Chile y celebrado entre los días 29 de septiembre y 30 de octubre de 2004. Agradezco a los organizadores la invitación a participar de esta reunión. Este artículo es parte de un proyecto mayor en ejecución, que cuenta con el apoyo de FONDECyT (proyecto 1010461).

${ }^{1}$ Weber, Economy and Society, 885; véase adicionalmente Kelsen, Teoría Pura del Derecho (1960), 255.
} 
Atria- Jurisdicción e independencia judicial: El Poder Judicial como poder nulo.

interpretativas y reglas del caso - no es una cosa mueble, entonces no cabe otra conclusión que la impunidad del hurto de electricidad.

Normalmente, estos principios informan la práctica de quienes interactúan habitualmente con estas instituciones o reflexionan sobre ellas. ¿Qué abogado no ha debido explicar la racionalidad subyacente al hecho de que sea parte de su deber profesional defender los derechos de una persona a pesar de saber o creer que ésta es culpable? Esta objeción (“¿cómo puedes defender a X si es culpable?") marca al que la formula como un no-abogado, porque ser abogado significa, entre otras cosas, entender por qué se justifica defender a alguien incluso si es culpable. No se trata de que el derecho y sus prácticas constituyan arcana a los cuales los legos no tienen acceso y sobre los cuales por consiguiente no pueden tener opinión (de hecho, el abogado habitualmente está en condiciones de explicar a satisfacción de su interlocutor la justificación de su deber defender al culpable); se trata, sin embargo, de que el abogado, que interactúa habitualmente con la práctica jurídica, o el profesor, que reflexiona sobre ella, están a veces en mejor posición que el lego para apreciar la justa dimensión de la crítica a la institución.

Por eso, cuando abogados, jueces o profesores discuten sobre la manera de mejorar o reformar (perfeccionar, como se dice hoy en día, como si las cosas pudieran ser perfeccionadas más de una vez) las instituciones jurídicas no es necesario hacer lo que dije al principio que creo que es necesario hacer: precisamente no necesitan comenzar desde primeros principios, porque ser abogado significa, entre otras cosas, que esos primeros principios son comunes. Que sean comunes es la significación del hecho de que todos nosotros estudiamos en las mismas escuelas y con los mismos manuales, que formamos parte de una misma práctica, una misma "cultura" jurídica. La importancia de esta cultura es que ella permite sostener reglas o instituciones que sirven alguna finalidad valiosa de un modo que puede a veces parecer contraproducente y absurdo. La importancia de poder perseguir esas modalidades de modos aparentemente contraproducentes o absurdos es que estas estrategias indirectas son a veces necesarias para la consecución de nuestras finalidades.

Dicho de otro modo, los principios reconocidos dentro de una cultura jurídica median entre las reglas y las finalidades que ellas persiguen (el principio de legalidad media entre la regla que sanciona el robo y la protección de la propiedad; pacta sunt servanda media entre la finalidad de facilitar la cooperación y el intercambio y la regla del artículo 1824 del Código Civil). La fractura de la cultura jurídica se denomina vulgarismo. El vulgarismo supone la renuncia a la idea de que el derecho pueda tener criterios internos artificiales de racionalidad o justificación, y lo entiende solamente de acuerdo a criterios externos de funcionalidad. El vulgarismo entiende instrumentalmente al derecho, y esa es por cierto su fortaleza, porque después de todo el derecho es un instrumento para lograr fines que no están dentro de él ${ }^{2}$. El problema es que esos fines sólo pueden ser logrados en la medida en que la autoconcepción del derecho no sea instrumental. Así, el principio de legalidad penal tiene una finalidad fuera de él: la de compatibilizar (e.g.) la protección de bienes a través de la amenaza de la sanción penal con la protección de la libertad personal. Entendiendo el principio de legalidad de un modo auto concientemente instrumental, entonces, el juez debería preguntarse, ante el primer hurto de electricidad: ¿qué es mejor en cuanto a sus consecuencias, extender ex-post el tipo de hurto a este caso o rechazar la acción por falta de tipicidad? Pero si el juez rechaza la acción porque este cálculo de consecuencias le indicó que eso era lo instrumentalmente adecuado, entonces está sacrificando la libertad protegida por

\footnotetext{
${ }^{2}$ Véase Atria, On Law and Legal Reasoning, cap. 1.
} 
el principio de legalidad; pacta sunt servanda se justifica porque facilita la cooperación y el intercambio en términos equitativos; pero el vendedor debe entregar la cosa porque la debe bajo el contrato, no porque entregarla es socialmente útil. Por supuesto, es socialmente útil que las partes de un contrato cumplan sus obligaciones, pero la finalidad instrumental del derecho de contratos se cumple solamente en la medida en que esta finalidad es opaca al momento de juzgar una acción particular ${ }^{3}$.

Para decirlo en otras palabras: los conceptos jurídicos no son conceptos naturales sino institucionales. Que sean conceptos institucionales quiere decir que es siempre posible en principio al menos distinguir entre la pregunta que se formula al interior de la institución (“¿es este contrato entre A y B válido?") de la pregunta que se formula sobre la institución ("¿es el derecho de contratos fundado en pacta sunt servanda justo o útil etc?") ${ }^{4}$. El vulgarismo niega la distinción entre estas dos preguntas, porque entiende que enfrentar la primera sin enfrentar la segunda es un "formalismo mecánico". Y así tiende a reducir al derecho a órdenes (del juez) respaldadas por amenazas.

Pues bien, la situación actual es que la función judicial y la jurisdicción son objeto de una comprensión fundamentalmente vulgarista. Pero nuestras prácticas judiciales están basadas sobre un modo particular de entender la función del juez y su relación con las normas del sistema jurídico, es decir, sobre una comprensión institucional. Ese modo institucional hoy no tiene muchos defensores explícitos; al contrario, la única referencia que se hace a él es para ridiculizarlo ("convierte a los jueces en aplicadores mecánicos" es usual oir). Pero lo que es así ridiculizado no es, en realidad, sino una versión caricaturizada y groseramente distorsionada de un ideal político que tiene alguna dignidad. Es este ideal el que será discutido en este artículo.

Esta reflexión es necesaria porque sin ella, nuestras discusiones sobre independencia y autonomía judicial son discusiones que carecen de densidad conceptual (para el abogado vulgarista la densidad conceptual es un formalismo estéril); no se trata de que sean debates en torno a cómo garantizar algo que todos sabemos que es importante garantizar, porque los principios sobre los cuales se basa la organización judicial son desconocidos o rechazados en el discurso público y académico. En definitiva, nuestras discusiones sobre lo que se llama actualmente el "gobierno judicial" (veremos más adelante que esto es un abuso de lenguaje) se orientan por la comprensión de diccionario de palabras como "independencia" y otras parecidas. Son discusiones vulgares en el sentido estricto del término, es decir, discusiones que no se benefician de un lenguaje o un aparato conceptual especialmente adaptado al asunto al que se refieren y que por eso abundan en confusión e ingenuidad.

No es necesario aquí identificar precisamente (más allá de lo indicado en el resto de esta introducción) las propuestas de reforma al régimen actual para mejorar la independencia judicial. Hacerlo sería, además de innecesario, un error, porque este artículo no tiene por finalidad directa abogar por u oponerse a algunas de esas propuestas. En vez de defender algunas propuestas contra otras, lo que quiero es reflexionar sobre la función judicial de un modo que ilumine la exigencia de independencia judicial. Aceptar el argumento de este artículo por supuesto implicaría rechazar algunas de las ideas que están en el ambiente y

\footnotetext{
${ }^{3}$ Véase Rawls, "Dos conceptos de regla".

4 ibid.
} 
Atria- Jurisdicción e independencia judicial: El Poder Judicial como poder nulo.

aceptar otras, pero mediatamente: como consecuencia de una comprensión profundizada de qué es lo importante cuando hablamos de independencia judicial.

Con el único objeto de mostrar lo necesario de una reflexión de este tipo quiero simplemente identificar algunas de las cuestiones que están en la discusión pública. En primer lugar, es cada vez mayor la insistencia, por los miembros del poder judicial y en particular por la Corte Suprema, en pro de la independencia financiera y económica de ese poder. Pero ¿por qué esta forma de independencia es importante? ¿Es esa independencia una que aumenta o disminuye la independencia del juez para resolver el caso conforme a derecho? ¿Qué es lo que se gana y qué es lo que se pierde con otorgar al poder judicial esta forma de independencia? Desde luego, que el poder judicial carezca de independencia económica pareciera minar su independencia, porque queda expuesto a las presiones del gobierno de turno que maneja, como dijera El Federalista, el mazo y la bolsa ${ }^{5}$. Pero ¿no será ésta una de esas situaciones aparentemente absurdas, como la del abogado que debe defender al inocente o el hurto de electricidad que era impune en Alemania, que puede ser justificada por esos principios sobre los cuales la institución judicial está construida? La respuesta es que no lo sabemos, porque en el debate no hay referencia a esos principios. El argumento en pro de la independencia económica se queda en la apariencia de las cosas, afirmando lo que es innegable: que en el sentido del diccionario de la Real Academia quien tiene un presupuesto garantizado es más independiente que el que tiene que solicitarlo año a año.

La otra idea que es reiterada una y otra vez es que el Poder Judicial (así, con las mayúsculas en cursiva, por razones que ya veremos) y que de hecho ha guiado el proceso de reforma de ese poder desde el retorno a la democracia, fue expresada por el Presidente Patricio Aylwin en su primera cuenta al país, cuando afirmó que lo que Chile necesitaba era "una reforma constitucional y legal del Poder Judicial encaminada a su modernización y a constituirlo en un auténtico Poder del Estado".

Esto se ha convertido en una cuestión reiterada, y ha sido asumido por la Corte Suprema como una finalidad de suma importancia. Así, por ejemplo, el presidente de esa corte sostuvo, al inaugurar el año judicial 2003:

Creemos que la modernización del Estado también debe extenderse a este Poder, fundamentalmente en los rubros que pasamos a referirnos, todos dirigidos a concretar su autonomía como característica inherente a la noción "poder del estado". No es suficiente la declaración formal de la Constitución Política en ese sentido, es imperativo perfeccionar ese reconocimiento frente a los otros Poderes, de modo que se traduzca en el plano normativo en leyes que la garanticen ${ }^{7}$.

En tanto poder del estado el Poder Judicial requiere, se dice, un tratamiento legal equivalente al de los otros poderes del estado, y en vez de eso lo que ha recibido ha sido un tratamiento similar al de un servicio público, y los jueces son concebidos como funcionarios,

\footnotetext{
5 The Federalist Papers, $\$ 78$.

${ }^{6}$ Mensaje Presidencial de inauguración de la $320^{a}$ Legislatura Ordinaria, en sesión de Congreso Pleno celebrada el 21 de Mayo de 1990.

${ }^{7}$ Ministro M Garrido M, Presidente de la Corte Suprema, discurso de inauguración del año judicial, 1 de marzo de 2003.
} 
no como detentadores de uno de los tres poderes del estado. ¿No será, sin embargo, que esta concepción del poder judicial se justifica por algún aspecto importante de la función que le corresponde en un estado de derecho? De nuevo, no lo sabremos mientras no intentemos superar la comprensión de las cuestiones propia de quienes no entienden el contexto institucional en que se plantean.

Como creo que las palabras anteriores no transmiten el sentido de ungencia del problema al que me refiero, quiero mencionar un caso de incomprensión supina de nuestros principios fundacionales por parte de quien desde luego debería conocerlos. El caso es notable no sólo porque ocurrió, sino porque además no tuvo ningún impacto ni reacción por parte de quienes conforman lo que antes denominé la "cultura jurídica"8.

En 2003 el poder legislativo aprobó un proyecto de ley que pretendía adecuar la legislación nacional a los acuerdos de la Organización Mundial del Comercio suscritos por Chile. Entre otras cosas, este proyecto regulaba el procedimiento de reclamación de los titulares de derechos de propiedad intelectual o industrial cuando éstos quisieran oponerse a la internación al país de alguna mercancía en violación de esos derechos. Como parte del procedimiento a seguir, el proyecto de ley autorizaba al juez a decretar la medida precautoria de suspensión del despacho aduanero de la mercancía. Adicionalmente, el proyecto disponía, en su artículo 12:

En ningún caso el tribunal que decretó la medida podrá disponer su alzamiento, sin que antes se le acredite el pago de los derechos, impuestos, tasas y demás gravámenes que pudieren afectar su importación.

El tribunal constitucional declaró esta disposición inconstitucional, sobre la base del siguiente argumento:

DECIMOTERCERO. Que, la norma en estudio vulnera en su esencia las facultades que, en relación con la concesión y término de medidas precautorias, todo tribunal tiene en ejercicio de la jurisdicción que el artículo 73, inciso primero, de la Constitución Política, le reconoce, puesto que sujeta el alzamiento de aquella a que se refiere, al cumplimiento de una condición por completa ajena a la convicción del juez competente, como es la que la propia norma contempla;

DECIMOCUARTO. Que tan evidente es lo anterior que en el Segundo Informe de la Comisión de Economía del Senado, recaído en el proyecto en examen, en su segundo trámite constitucional, se indica "como se puede apreciar, esta norma viene a poner límite a una facultad de los tribunales ...", siendo ésta, precisamente, la razón por la cual se la calificó como propia de ley orgánica constitucional;

La ley fue declarada inconstitucional, en otras palabras, porque limitaba una facultad de los tribunales al sujetar el alzamiento de una medida precautoria a una requisito adicional a la convicción del juez. Ésta es una clara instancia del problema al que me refería al principio. La diferencia entre la autocomprensión del derecho y la comprensión vulgarista del Tribunal Constitucional es tan enorme que uno no sabe por dónde comenzar. ¿Qué ley

8 Con la excepción de Correa, "Tribunal Constitucional”, 523s. 
Atria- Jurisdicción e independencia judicial: El Poder Judicial como poder nulo.

se salva de este supuesto reproche de constitucionalidad? O mejor: ¿No se define el estado de derecho precisamente porque la ley, expresión de la voluntad soberana, limita las facultades del juez para resolver de acuerdo a su convicción? ¿Es la posibilidad de hacer esto lo que el Tribunal Constitucional ha declarado que es contrario a la constitución?

\section{Bocas de las leyes}

La situación actual, entonces, es una en la que debemos reformular los principios que subyacen a nuestras instituciones jurídicas. Para hacerlo lo mejor es volver atrás, a esos momentos en los cuales los principios no eran evidentes porque eran novedosos. Deberemos preguntarnos si es posible encontrar en las razones ofrecidas entonces los materiales suficientes para construir un sistema que resulte atractivo para nosotros, o si por el contrario debemos abandonarlos y abrazar el giro vulgarista del derecho chileno.

Permítanme comenzar considerando con cierto detalle una de las afirmaciones más famosas de la historia sobre la función judicial:

Podría ocurrir que la ley, que es ciega y clarividente a la vez, fuera, en ciertos casos, demasiado rigurosa. Los jueces de la nación no son, como hemos dicho, más que la boca que pronuncia las palabras de la ley (la bouche que prononce les paroles de la loi), seres inanimados que no pueden moderar ni la fuerza ni el rigor de las leyes. La parte del cuerpo legislativo que considerábamos como tribunal necesario, anteriormente, lo es también en esta ocasión: a su autoridad suprema corresponde moderar la ley a favor de la propia ley, fallando con menos rigor que ella?.

La primera cuestión que es importante destacar es que aquí Montesquieu no intenta describir ningún sistema jurídico en particular (aunque el tema del libro 11 es la constitución inglesa). El tema que está siendo considerado por Montesquieu es cómo puede ser preservada la libertad. Y el descubrimiento de Montesquieu fue que la libertad sólo puede ser preservada cuando hay división de poderes, de modo que la vida, la libertad o la propiedad de uno no estén entregadas a la voluntad de ningún individuo en particular, en especial no al juez:

Cuanto más se aproxima el gobierno a la república, más fija será la manera de juzgar [....] En Inglaterra el jurado decide si el acusado es culpable o no del hecho que se le presenta; si es declarado culpable, el juez impone la pena que la ley señala para aquel hecho, para lo cual no necesita más que tener ojos ${ }^{10}$.

Aplicado a la organización judicial, esto requería independencia judicial: "tampoco hay libertad si el poder judicial no está separado del legislativo ni del ejecutivo" "Este principio de separación de poderes está, sin embargo, sujeto a excepciones, y es en el curso de la enumeración de estas excepciones que Montesquieu de un modo muy incidental y

\footnotetext{
${ }^{9}$ Montesquieu, Del Espiritu de las Leyes, libro 11 cap. 6, p. 112.

10 ibid, libro 6 cap. 3, p. 56.

11 ibid, libro 11 cap. 6, p. 107.
} 
aparentemente sin conciencia de la importancia que la frase tendría para el desarrollo de la ciencia jurídica continental, formula su caracterización del rol del juez.

Esta segunda excepción discutida por Montesquieu trataba del problema de lo que hoy en teoría del derecho sería llamado la "derrotabilidad" de las reglas jurídicas, que se refiere al hecho de que "podría ocurrir que la ley, que es ciega y clarividente a la vez, fuera, en ciertos casos, demasiado rigurosa" 12 .

Quiero detenerme un instante en esta frase precisa, porque en ella está contenida una idea extraordinariamente importante. Montesquieu dice que la ley es ciega y clarividente a la vez. Es ciega porque ignora en principio todo lo que ella misma no hace relevante. Así, por ejemplo, el inciso $4^{\circ}$ del art. 9 del Código del Trabajo dispone que

Si el empleador no hiciere uso del derecho [a enviar una copia del contrato a la Inspección del Trabajo para que ésta requiera de firma al trabajador, ante la negativa de éste a firmar el contrato de trabajo], la falta de contrato escrito hará presumir legalmente que son estipulaciones del contrato las que declare el trabajador.

Que la ley sea ciega quiere decir que ella sólo tiene ojos para ver si se trata de un contrato de trabajo o no, y en caso afirmativo si el empleador ha ejercido o no el derecho que le confiere el inciso $3^{\circ}$ del mismo artículo. Si se trata de un contrato de trabajo que no se ha escriturado, y si el empleador no ha ejercido ese derecho, entonces la presunción legal se aplica; si cualquiera de estas dos condiciones no concurre, no se aplica. La ley es ciega a todo lo demás.

Pero no es sólo ciega; es también clarividente, porque es precisamente porque se trata de un contrato de trabajo que no ha sido escriturado y porque el empleador no ha ejercido el derecho que le confiere el inciso $3^{\circ}$ del artículo 9 que ha de creérsele al trabajador. La ceguera y la clarividencia de la ley no son, en otras palabras, sino una y la misma característica: su formalidad, que excluye de consideración lo que no es relevante y así hace posible una decisión del caso, único e irrepetible como todos los casos, de acuerdo solamente a lo que es relevante.

Pero la cuestión no es tan simple, porque la misma ley que es ciega y clarividente puede ser "demasiado rigurosa". Montesquieu no se está refiriendo aquí al exceso de rigor, por ejemplo, del artículo 450 del Código Penal, que sanciona a la tentativa de ciertos delitos contra la propiedad como si fueran consumados. Aquí para moderar el rigor de la ley uno tendría que derogarla13. No sería un caso de lo que hablaba Montesquieu, de "moderar la ley por la ley misma", sino de moderar la ley por otras finalidades. No cabe duda de que leyes excesivamente rigurosas como el artículo 450 del Código Penal deben ser derogadas, pero no por respeto al artículo 450 del Código Penal, sino porque son injustas. Es obvio también que el poder para derogar el art. $450 \mathrm{CP}$ corresponde al poder legislativo, y no como una excepción al principio de separación de los poderes, sino en cumplimiento de él.

\footnotetext{
12 Sobre el problema de la derrotabilidad de la ley, véase Atria, Law and Legal Reasoning, y Atria, "Las circunstancias de la derrotabilidad".

${ }^{13}$ Véase Bascuñán, "Delitos contra intereses patrimoniales", 314-329.
} 
Atria- Jurisdicción e independencia judicial: El Poder Judicial como poder nulo.

Los casos a los que Montesquieu hace referencia son casos en los que la ley debe ser moderada no porque moderarla sería más justo (y entonces se modera la ley en busca de la justicia) sino casos en los que la ley debe ser moderada por la ley misma. Y permítanme mencionar uno de esos casos, que ha sido recientemente decidido por la Corte Suprema. Aquí el trabajador cuyo contrato no estaba escriturado era el gerente de una empresa, y si bien carecía de facultades para autocontratar, era él quien debería haber tomado, a nombre de la empresa, la decisión de ejercer el derecho del artículo 9 inciso $3^{\circ}$ del Código del Trabajo. Él mismo decidió no ejercerlo y no escriturar el contrato, y cuando fue despedido demandó a su empleador alegando que su caso estaba cubierto por la presunción del inciso $4^{\circ}$ del artículo 9 .

La ley aquí es demasiado rigurosa, porque parte de lo que ley no ve por su ceguera es que éste no es un caso típico de esos que el derecho laboral regula. El supuesto central del artículo 9 (y de todo el derecho del trabajo) es que el trabajador no está en igualdad de condiciones para negociar con su empleador, y la ley busca compensar esa desigualdad mediante reglas como las del artículo 9. Por supuesto, la regla del artículo 9 es inaceptable cuando las partes están en igualdad de condiciones, porque en ese caso la ley, como el Código Civil, mantiene su neutralidad entre ellas. No hay razón por la que la ley haya de creer a un contratante más que al otro cuando ambos están en igual posición. Y esa era la situación en Sternsdorf con Manaplast (sentencia de la Corte Suprema de fecha 17 de marzo de 2003, rol 3236-02), y por eso puede decirse que en este caso el artículo 9 del Código del Trabajo debía ser moderado en su alcance no porque sea injusta la presunción de ese artículo, sino porque decidir este caso conforme a esa regla era contrario a esa regla. La ley debía ser moderada por la ley misma.

La segunda excepción de Montesquieu al principio de separación de poderes concierne casos como éste; y, continuaba Montesquieu, como de lo que se trataba era de corregir la ley que no limitaba su aplicación del modo que debía, el que debía corregirla era el que tenía autoridad para hacerla y modificarla, y por eso Montesquieu aquí recomendaba (en un consejo que fue seguido, con escaso éxito, por los revolucionarios franceses) la creación de una comisión parlamentaria a la que el juez, cuando se encontrara con estos casos, remitiera el asunto suspendiendo el procedimiento.

Montesquieu no desarrolla en El Espíritu de las Leyes esta idea de la ley que debe ser moderada por la ley misma, pero para avanzar en esta cuestión podemos recurrir a uno de los más grandes juristas del siglo XIX cuyas ideas sobre esta materia en algún sentido están muy cerca de las de Montesquieu. Me refiero a F. K. von Savigny, y a su obra más importante, el Sistema del Derecho Romano. Ahí, Savigny identifica dos causas por las cuales una ley puede ser "defectuosa” y necesitar interpretación:

Primera, expresión indeterminada, no conteniendo ningún pensamiento concreto; Segunda, expresión impropia, cuyo sentido está en contradicción con el verdadero pensamiento de la ley ${ }^{14}$.

Refiriéndose a las leyes de expresión incompleta, Savigny aclara:

\footnotetext{
${ }^{14}$ Von Savigny, Sistema del Derecho Romano Actual, 155.
} 
La expresión incompleta de una ley tiene precisamente el carácter de un discurso interrumpido que deja, por tanto, en suspenso su sentido; tal sería una ley que exigiera testigos en un punto cualquiera y no fijase su número. Una ley es, por su parte, de expresión impropia, cuando da un sentido claro y determinado, pero diferente del pensamiento real de la ley. En vista de esta contradicción se pregunta cuál debe prevalecer; ahora bien, siendo la palabra el medio y el pensamiento el objeto, debe aquélla subordinarse a éste. Con el cual debe establecerse relación de conformidad y, en su virtud, rectificarse la expresión (ibid).

Ya hemos mencionado un caso de ley de expresión impropia: el del artículo 9 del Código del Trabajo en Sternsdorf con Manaplast, porque el "pensamiento" (propósito, sentido ${ }^{15}$ ) de la ley no es beneficiar al gerente que abusa de su poder como tal para obtener la no escrituración de su contrato y luego demandar en virtud de la presunción legal. El pensamiento de la ley no beneficia al gerente, pero su expresión si. La expresión es impropia manifestación del sentido de la ley.

Según Savigny, en casos de estos dos tipos es necesario corregir el "defecto" de la ley. Pero siendo distinto el defecto la manera de corregirlo es también diversa. El defecto de las leyes de expresión indeterminada "debe ser en todo caso corregido y no ofrece peligro alguno". La razón por la que debe ser corregido es porque si no es corregido no hay ley que aplicar. El defecto de expresión impropia, por su parte, "es más delicad[o] de tratar y pide mayores precauciones"16. Aquí la interpretación es necesaria para "rectificar la expresión" y así "poner en armonía la forma con el pensamiento"17. La diferente función de la interpretación en relación a las leyes defectuosas por estas dos razones y la explicación de las mayores precauciones que son necesarias en el caso de leyes de expresión impropia son elegantemente explicadas en un pasaje que merece ser citado completo:

Los procedimientos con ayuda de los cuales se corrige una expresión impropia difieren mucho de los empleados para fijar una expresión indeterminada; Primeramente se supone que existe un pensamiento determinado bajo una expresión defectuosa; esta relación no admite como la indeterminación pruebas lógicas, sino solamente pruebas históricas y es, por consiguiente, menor su certidumbre y susceptible de diversos grados. Otra circunstancia aumenta todavía la dificultad de la materia: la expresión es el signo más inmediato y más natural del pensamiento, y precisamente no lo negamos en el caso presente. La expresión indeterminada exige necesariamente el remedio de la interpretación pues sin ella no hay ley ni texto que aplicar: aquí, por el contrario, la letra de la ley nos da un sentido claro y susceptible de aplicación. Por último, cuando se trata de una expresión indeterminada la operación que señala el defecto no es la que lo corrige: aquí las dos operaciones se confunden. En efecto, juzgamos que es impropia la

\footnotetext{
15 "Empleo la palabra pensamiento, como la más propia para expresar la parte intelectual de la ley. Otros emplean la palabra sentido. Es preciso evitar el término intención, porque tiene un doble significado, pues puede aplicarse al fin inmediato de la ley, como al mediato a que indirectamente concurre" ibid, 149n.

16 ibid, 155.

17 ibid, 160
} 
Atria- Jurisdicción e independencia judicial: El Poder Judicial como poder nulo.

expresión comparándola con el pensamiento real de la ley; luego para conocer esta impropiedad es preciso que nos sea conocido el pensamiento, en cuyo caso hemos encontrado ya el remedio ${ }^{18}$.

Las leyes de expresión indeterminada tienen un defecto lógico, uno que es, en consecuencia, tan determinable para el juez como lo es para el legislador. Por eso el legislador tiene la oportunidad de modificarla, corrigiendo la indeterminación de la expresión, si así lo quiere. Si no lo quiere o no lo hace, la expresión indeterminada puede ser determinada a través de métodos aceptados de interpretación y argumentación. En todo caso, no hay, no puede haber, un problema de que el juez usurpe el poder legislativo, porque tratándose de leyes de este tipo si la indeterminación no es solucionada no hay ley aplicable: el sentido de la norma ha quedado en suspenso. Por esto permitirle al juez determinar la expresión indeterminada de la ley no es peligroso en absoluto.

La cuestión es completamente distinta, sin embargo, tratándose de leyes de expresión impropia: aquí tratamos con una ley (como el art. 9 del Código del Trabajo) cuyo significado es claro y determinado, y es defectuoso sólo porque el juez le asigna un pensamiento que se opone a su significado: antes de alcanzar la conclusión de que la expresión es impropia el juez necesitará haber determinado cuál es este pensamiento de la ley. Pero la manera principal en que el sentido de la ley puede ser conocido es a través de su expresión. Por eso el problema con las leyes de expresión impropia es el advertido por Savigny, que tratándose de ellas no siempre es claro si el pensamiento que resulta de nuestra interpretación es realmente el pensamiento del legislador o el que hubiera debido tener, en cuyo último caso la interpretación corregiría, no la [expresión], sino el pensamiento mismo ${ }^{19}$.

Esto explica por qué el hecho de darle el poder para rectificar la expresión de la ley al parlamento debe ser concebido, como para Montesquieu, como una excepción al principio de separación de lo poderes. Por supuesto no es excepción a ese principio que el legislador ejerza los poderes que en principio le corresponden; lo que es excepcional es que ejerza poderes que en principio no le corresponden y que sin embargo es prudente asignarle. La razón por la cual es prudente asignarle esta parcela de la jurisdicción al legislador, para Montesquieu, es el peligro de Savigny: que el juez, "a pretexto" (para usar la expresión de nuestro Código Civil) de corregir la impropiedad de la expresión, cambie la ley, convirtiéndola en la ley que a él le habría gustado que se dictara.

\section{Justificación y aplicación}

Quiero ahora detenerme en las leyes de expresión impropia y en particular en las razones por las cuales la impropiedad de la expresión no es un "defecto" de las leyes, como lo concebía Savigny, sino una características necesaria de ellas, al menos dado el modo en que concebimos el derecho en el mundo moderno. Ello nos proveerá, espero, del principio que después nos guiará cuando discutamos cuestiones de estado de derecho y poder judicial. En efecto, como no es un defecto de la ley quien corrige la impropiedad de la expresión no corrige la ley, es decir, no ejerce una potestad legislativa.

\footnotetext{
18 ibid, 160-161.

19 ibid, 162.
} 
Veremos que una buena manera de comenzar a tratar este problema es preguntando lo obvio: ¿por qué los jueces son necesarios? ¿no podrían ser reemplazados por computadores?

Es importante notar que la respuesta a esta pregunta no es tan obvia como parece. Por supuesto, los jueces determinan los hechos del caso mediante la prueba, pero la fijación de hechos no corresponde al núcleo de la función judicial. En el derecho comparado es habitual que la función de dar hechos por probados corresponda a un grupo de legos, el jurado. Pareciera que en cuanto a la aplicación de reglas sólo limitaciones tecnológicas impiden que los jueces sean reemplazados por computadores: un jurado podría decidir sobre los hechos, y el sistema proveería de la solución correcta.

El mejor contexto para discutir estas cuestiones es el provisto por la teoría del discurso, de acuerdo a la cual una regla es válida (justificada, correcta) si puede mostrarse, a través del discurso racional, que ella es aceptable racionalmente por todos los afectados. Esta condición se denomina principio de universalización, y consiste en (U) que todos los involucrados puedan aceptar las consecuencias y efectos colaterales que la observancia universal de la norma tendrá para la satisfacción de los intereses de cada interesado.

Supongamos que la regla del art. 9 del Código del Trabajo es efectivamente aceptable para todos. ¿Qué pasa en casos especiales, como el de Sternsdorf con Manaplast? Esto puede ser iluminado recordando un problema que enfrentó a Kant con Benjamín Constant $^{20}$ : Podemos estar de acuerdo que, en general, va en el interés de todos que reconozcamos una obligación de decir la verdad; "no mentirás", entonces, es una norma justificada, es decir, una norma que satisface (U). Sin embargo, ¿qué ocurre si la policía secreta de un régimen terrorista aparece en mi puerta preguntando por el paradero de mi amigo que está huyendo de ella? Enfrentado a un caso como éste, uno podría pensar que al momento de asentir en el discurso a la norma "no mentirás" pasamos por alto casos de este tipo, porque en estas circunstancias lo que iría en el interés de todos es que podamos (o incluso, debamos) mentir para salvar al inocente. Para solucionar esta inadvertencia, pareciera que deberíamos volver al discurso, y preguntarnos si este caso está cubierto por una excepción que a su vez pueda ser justificada de acuerdo a $(U)^{21}$.

Aquí, sin embargo, enfrentamos una disyuntiva familiar. Podemos introducir a nuestra norma justificada ("no mentirás") una excepción concreta (como: "mentir es permisible si es necesario para salvar la vida de un inocente injustamente perseguido por la policía secreta de un régimen terrorista") o podemos formularla en términos abstractos ("mentir es permisible cuando es correcto mentir, habiendo considerado todas las cosas"). Si adoptamos la primera solución, tendremos que permanecer abiertos a la posibilidad de un nuevo caso especial en el futuro, en que una nueva excepción concreta será necesaria. Pero entonces del hecho de que aceptemos una norma universal como "no mentirás" no se sigue que tengamos el deber de no mentir en un caso particular, porque después de todo ese caso particular podría ser un nuevo caso excepcional. La norma así no guía la acción en caso alguno. Si adoptamos la segunda solución, por otra parte, entonces podemos decir que la norma obliga en cada cado, porque sólo nos obliga a decir la verdad si es correcto decir la verdad, pero entonces deviene irrelevante. Uno tiene el deber de decir la verdad cuando es

\footnotetext{
20 Kant, "Sobre un presunto derecho de mentir por filantropía"; Constant, Curso de Política Constitucional.

${ }^{21}$ Véase Atria, "Circunstancias de la derrotabilidad".
} 
Atria- Jurisdicción e independencia judicial: El Poder Judicial como poder nulo.

correcto decir la verdad porque es correcto decir la verdad, no porque haya una norma que nos obligue a decir la verdad cuando es correcto decir la verdad. Esta última norma es redundante. De modo que parece que las normas generales o son ciegas a los casos particulares, o son redundantes, o no guían la conducta.

Una manera de evitar este dilema es adoptar una versión más fuerte de (U):

$\left(\mathrm{U}_{\mathrm{f}}\right)$ Una norma es válida y apropiada para cada caso si las consecuencias y efectos colaterales que se siguen de su observancia universal pueden ser aceptadas por todos los potencialmente involucrados.

Pero es simplemente imposible saber cuáles serán las consecuencias y efectos colaterales de la aplicación de una norma a cada caso posible, porque esos casos son inesperados e imprevisibles. No hay un método que nos permita estar seguros de que todos los casos han sido enumerados. La clase de casos posibles es infinita (al menos para todos los efectos prácticos). Entonces pareciera que el principio de universalidad, en su primera versión, hace a las normas inútiles o redundantes, mientras que en su versión fuerte hace a las normas imposibles de justificar.

Una salida a este problema es fracturar el principio de universalidad en dos principios: uno que controla la validez universal de la norma y otro que controla la adecuación de la norma a un caso particular. El primero entiende la idea de imparcialidad que subyace a $U$ en un sentido universal y recíproco (" $¿ H a n$ sido tomados igualmente en cuenta los intereses de todos los afectados por la norma?"), mientras el otro entiende la imparcialidad en un sentido aplicativo (" ¿Es la norma de cuya aplicación se trata una que al ser aplicada al caso trata imparcialmente los intereses de todos lo involucrados en él?”). Así,

lo que es relevante para la justificación es la norma misma, independiente de su aplicación a un caso particular. Es una cuestión de si va en el interés de todos que todos siguieran la norma. Si una norma encarna o no el interés común de todos no es una cuestión que dependa de su aplicación, sino de las razones que pueden ofrecerse para que la norma deba ser observada como una regla por todos. Lo que es relevante para la aplicación, en contraste, es la situación particular, independientemente de si la observancia general va en el interés de todos. Es una cuestión de si y cómo la norma debe ser seguida en una situación particular en vista de todas las circunstancias particulares de ésta ${ }^{22}$.

Entonces: la pregunta sobre si se justifica la norma "no mentirás" puede ser respondida ceteris paribus: para determinar si esa norma satisface U no es necesario examinar las consecuencias que de ella se siguen para cualquier caso concebible, porque lo que resulta crucial son las razones en virtud de las cuales esa norma es aceptable.

Volvamos ahora a Sternsdorf con Manaplast. si el trabajador es un gerente, y de él depende la decisión de escriturar o no su propio contrato de trabajo, ¿puede alegar en su

${ }^{22}$ Günther, The Sense of Appropriateness. 
beneficio la presunción del artículo 9 del Código del Trabajo ante el hecho de que él decidió no escriturar el contrato? A mi juicio, es un error responder: "si, si puede, porque el artículo 9 del Código del Trabajo no hace distinciones entre trabajadores ordinarios y gerentes". Pero ¿implica esto que el artículo 9 debe ser modificado y que una excepción para los gerentes debe ser incorporada a éste? La respuesta no es obvia: ¿deben ser incluidos también en la excepción los sub-gerentes? ¿Qué pasa con el que formalmente no controlaba la decisión de escriturar, pero que en los hechos podía decidir si hacerlo o no? El simple artículo 9 del Código del Trabajo debería ser convertido en una larga y detalla regla que hiciera referencia a todos los casos en los cuales se aplica la presunción y los casos a los que no se aplica. Pero tiene valor que la ley sea clara y fácilmente entendible, particularmente en materias como la laboral. De modo que no parece sensato que el legislador se sienta interpelado por la decisión de la Corte Suprema a modificar el artículo 9 del Código del Trabajo.

Pero si el artículo 9 no hace la distinción entre gerentes y otros trabajadores, ¿cómo hemos de justificar una decisión como la de la Corte (que negó la aplicabilidad del art. 9 CT al caso)? Aquí es donde aparece la relevancia de la discusión anterior. El legislador ha considerado el problema, y ha decidido que dada la desigualdad de poder negociador que es típica de la relación empresario-trabajador no va efectivamente en el interés de todos que las reglas generales de contratación sean las que gobiernen el contrato de trabajo. Es más imparcial, desde el punto de vista de los intereses de todos, compensar normativamente la desigualdad empírica de trabajador y empresario. Sólo a través de esta función compensatoria de la ley laboral el legislador puede ser, en un sentido profundo, imparcial entre los intereses de trabajadores y empleadores. Esto quiere decir que el artículo 9 es una norma justificada, es decir, una norma que es imparcial y que va en el interés de todos los involucrados. Que la norma esté justificada quiere decir que, salvo en circunstancias especiales, el juez debe decidir los casos conforme a ella. El "salvo circunstancias especiales" es importante porque es precisamente lo que nos provee la clave para entender la necesidad de la jurisdicción.

Como consecuencia del hecho de que las leyes incluyen de modo tácito esta cláusula, la aplicación de una ley a un caso cubierto por su significado literal puede ser derrotada cuando el caso es especial, y aquí la especialidad del caso permite que el juez niegue la aplicación de la norma al caso sin negar la obligatoriedad ni la validez de la norma en cuestión. Esto es lo que un computador no puede hacer; ésta es la razón por la que los jueces no pueden ser reemplazados por computadores. Esto es lo que caracteriza la función judicial. Un juez (sin perjuicio de que tenga otras funciones) es quien tiene el deber de aplicar normas generales a casos particulares, obligación de aplicación que no es "mecánica" sino que incluye la obligación de asegurar que el caso no es en algún sentido lo suficientemente "anormal" como para que la norma que conforme a su significado es aplicable deba ser aplicada $^{23}$. Ahora podemos decir, con Montesquieu, que el juez es un aplicador de leyes, pero no estamos obligados a dar a la palabra "aplicador" la comprensión que se sigue de la manera ingenua de entender la división de poderes entre legislativo y judicial. El juez es un aplicador, no un "mero" aplicador, de leyes. Aplicar las leyes significa determinar si el caso es cubierto por el significado de una regla general, y si lo es, decidir que el caso debe ser

\footnotetext{
${ }^{23}$ Esta cuestión (i.e. la de la distinción entre modificar una norma y adecuar su aplicación) es una de las que es discutida reiteradamente en Atria, Bulygin, Moreso, Navarro, Rodríguez y Ruiz Manero, Lagunas del Derecho.
} 
Atria- Jurisdicción e independencia judicial: El Poder Judicial como poder nulo.

resuelto por la aplicación de la regla general o si la regla general está formulada de modo impropio para el caso por lo que debe ser adecuada a éste.

Nótese cómo esta distinción entre justificación y aplicación de normas nos provee de un principio que nos orienta en la comprensión de nuestras instituciones. Si el legislador debe crear nuevas normas generales (legislación es el nombre que le damos a la creación conciente de nuevas normas generales), entonces deberá asegurar, en la medida de lo posible, que las normas que sean creadas cumplan con la exigencia de (U): que ellas reflejan adecuadamente los intereses de todos los involucrados. Por eso el cuerpo legislativo en todos los sistemas democráticos es siempre una asamblea que en principio al menos pretende representar a todos los miembros de la comunidad política del caso. El legislador no necesita considerar ningún caso particular. Lo que el legislador necesita es considerar la norma de cuya justificación se trata, a la luz de las razones que para ella se pueden ofrecer, y decidir si desde el punto de vista de todos los representados esa norma es imparcial, si toma en cuenta los intereses de todos. Por eso no hay división de funciones dentro de las cámaras legislativas: cada diputado y cada senador tiene la misma función y la misma autoridad que el siguiente, porque todos representan en la misma medida.

Pero el juez no necesita representar a nadie. Lo que aparece ante el juez es una norma que ya ha sido sometida al proceso parlamentario y legislativo de justificación, y por esto el juez no debe volver a preguntarse si la norma representa adecuadamente los intereses de todos los involucrados. Por supuesto, es posible que el juez crea que no lo hace, que ha habido un error legislativo, pero en tanto juez su deber es no dejar que esas consideraciones afecten su juicio. Debido a la fractura del razonamiento práctico que hemos introducido hay, sin embargo, una decisión que el legislador no ha tomado, por la que el juez no puede respetarla (no puede respetarse una decisión que no ha sido tomada): el legislador no ha decidido que la norma es aplicable a todos los casos cubiertos por el significado literal de la norma ${ }^{24}$. El legislador sólo ha considerado la aplicación de la norma a los casos típicos, por lo que el juez deberá determinar si el caso delante de él es un caso típico o no lo es. Por eso nuestras instituciones judiciales están diseñadas para maximizar la posibilidad de que todo elemento relevante del caso concreto delante del juez sea sujeto a un escrutinio lo más cercano posible. Esto se conecta con lo que siempre ha sido característico de la función judicial: que trata de la aplicación de la ley a casos particulares y singulares. Ahora podemos entender aquello de res ipsa loquitur, los hechos hablan por si mismos. Esta afirmación es absurda si se entiende en el sentido de que los hechos tienen normatividad inmanente ${ }^{25}$. Los hechos por supuesto reciben una significación institucional en virtud de reglas constitutivas $^{26}$, y en este sentido ellos no ipsae loquuntur, no hablan por si mismos. Pero teniendo esta (importante) prevención en mente es posible entender que el sentido de esa regula iuris es enfatizar que el juez debe dejarse impresionar por el caso singular ante él. En algún sentido metafórico pero no completamente imaginario, la jurisdicción consiste en dejar que los hechos hablen, en atender al caso para poder apreciarlo en sus propios términos y decidir si es un caso especial o no lo es. Por eso también encontramos que nuestras reglas procesales distinguen funciones entre los participantes de procesos judiciales: cada parte con

\footnotetext{
${ }^{24}$ Detmold, "Law as practical reason".

25 Porque, como correctamente sostuvo Hart, "las situaciones de hecho no esperan al juez claramente etiquetadas con la regla que les es aplicable" (Hart, "Problems of the philosophy of law", 106).

${ }^{26}$ Véase Searle, Actos de Habla.
} 
sus abogados, el juez con autoridad. No se da en un juicio la igualdad de funciones que encontramos en las cámaras legislativas ${ }^{27}$.

\section{El poder judicial como poder nulo}

Ya tenemos, entonces, un principio que orienta tanto la distribución de competencias entre jueces y legisladores como las características institucionales que cada uno de estos órganos debe reunir. En efecto, las consideraciones anteriores muestran que, así como para el poder legislativo lo crucial es la capacidad de representar los intereses de todos los afectados por la norma de cuya aprobación se trata, para la función judicial lo determinante es la capacidad del juez de examinar tan detalladamente como sea posible la configuración peculiar del caso particular ante él. Este examen del caso debe ser conducido sólo mirando si, junto a las propiedades que de acuerdo a las reglas justificadas (i.e. válidas) son relevantes, concurren en él propiedades que lo hacen anormal, para decidir sobre la correcta aplicación de las reglas legales a su solución.

Esto explica desde luego muchas de las características más familiares de la organización judicial en un estado de derecho: la inamovilidad de los jueces, su fuero, etc. Éstas son prerrogativas que no pueden entenderse como las del trabajador en el Código del Trabajo: no miran al interés del juez, sino a que al considerar el caso el juez no deba tomar en cuenta la manera en que su consideración y decisión del caso tendrán o no impacto en su empleo. Todo esto es suficientemente obvio.

Menos obvio, sin embargo, es otro punto, también destacado por Montesquieu pero menos famoso:

El poder judicial no debe darse a un Senado permanente, sino que lo deben ejercer personas del pueblo, nombradas en ciertas épocas del año de la manera prescrita por la ley para formar un tribunal que sólo dure el tiempo que la necesidad lo requiera. De esta manera el poder de juzgar, tan terrible para los hombres, se hace invisible y nulo, al no estar ligado a determinado estado o profesión. Como los jueces no están permanentemente a la vista, se teme a la magistratura, pero no a los magistrados ${ }^{28}$.

Este pasaje resiste dos interpretaciones. La más común, apoyada en la última frase, es que como el juez es la boca que pronuncia las palabras de la ley mientras la boca pronuncie las palabras que debe pronunciar resulta indiferente de quién es la boca, y por eso la persona del magistrado es invisible. Pero la segunda oración de esta afirmación ("el poder de juzgar se hace invisible y nulo") no se refiere a la invisibilidad del magistrado sino a la invisibilidad del poder de juzgar, y es esta idea la que quiero considerar a la luz de las argumentaciones anteriores. Nótese además que la tesis central de este pasaje no es la indicada en la primera frase (que no debe darse el poder judicial a un senado permanente) sino en la segunda (que el poder de juzgar es invisible y nulo). Montesquieu creyó que la forma de asegurar la inexistencia e invisibilidad del poder de juzgar era nombrar jueces

\footnotetext{
${ }^{27}$ Un hecho notado por Habermas, Facticidad y Valides, 240s.

28 Montesquieu, Espiritu de las Leyes, libro 11 cap. 6, p. 108.
} 
Atria- Jurisdicción e independencia judicial: El Poder Judicial como poder nulo.

temporales. En esto no fue seguido ni siquiera por los revolucionarios franceses. El hecho de que la forma precisa en que Montesquieu quería asegurar lo que era importante no fue aceptada no quiere decir que esa finalidad no fuera aceptada. Al contrario, quiero explicar el sentido en que es posible entender nuestro sistema institucional como un esfuerzo de hacer del poder de juzgar un poder invisible y nulo.

Es importante especificar el sentido en el que el poder judicial es un poder nulo. Montesquieu supone esta especificación, aunque no la desarrolla: "de los tres poderes de que hemos hablado el de juzgar es, en cierto modo, nulo" 29 . Quiero decir dos palabras acerca de estas tres palabras, "en cierto modo".

Desde luego no es la autoridad del juez para decidir un caso particular la que es invisible y nula. Para las partes el poder del juez es claramente visible (y no se ve cómo podría dejar de serlo, o cómo podría pensarse que es bueno que deje de serlo). El "cierto modo" en que ese poder era invisible es el del artículo 3 del Código Civil: la tesis debe ser que, más allá de la visibilidad propia respecto de las sentencias en las causas en que actualmente se pronunciaren, el poder de juzgar es invisible y nulo.

Y la razón es simplemente que el Poder Judicial no existe. Si no entendemos por qué el poder judicial, en tanto poder del estado, debe ser nulo e invisible no entenderemos muchas de las características más sobresalientes de su configuración institucional.

\section{La expresión "Poder Judicial” como abreviatura}

Al decir que el poder judicial no existe me refiero a que, en tanto poder del estado, no hay uno que sea el Poder Judicial. Hay jueces, y ellos tienen autoridad, pero no hay un poder judicial. Cada vez que hablamos propiamente del poder judicial estamos usando una abreviación para referirnos a todos los jueces. Cada vez que hablamos del Poder Judicial como un órgano del estado estamos incurriendo en una impropiedad del lenguaje o una sub-versión de las instituciones. El poder judicial en tanto tal carece de unidad de agencia, no es un agente colectivo (por eso debe en su sentido propio escribirse con minúsculas, y por eso he estado usando las mayúsculas en cursivas cuando me refiero al poder judicial en el sentido impropio, como "Poder" del Estado).

Compárese la situación con el poder legislativo: no es posible decir que "poder legislativo" sea una abreviación para hacer referencia a los miembros de las cámaras, porque cada miembro de una cámara no tiene autoridad en la forma en que la tiene el juez. La expresión "poder legislativo" indica a un tipo especial de agente colectivo, es decir, una pluralidad de individuos que es entendido por el sistema jurídico como un agente. Es el poder legislativo, y no la mayoría de ambas cámaras, el que aprueba una ley. Toda la autoridad que tiene un diputado o senador la tiene en virtud de que contribuye a formar la voluntad de un agente colectivo.

29 ibid, libro 11 cap. 6, p. 110, cursivas agregadas. 
La situación del poder judicial desde este punto de vista es radicalmente distinta. No es el poder judicial el que decide un caso o dicta una resolución, es el tribunal respectivo. El poder judicial no actúa, no aparece. Sólo aparece el tribunal. Como un Poder del Estado que actúa en tanto tal, uno que ha de escribirse con mayúsculas, el poder judicial no existe.

De modo que la queja habitual que mencionaba al comienzo de que el poder judicial no es un "auténtico poder del estado" y que eso constituye un defecto a ser corregido, se basa simplemente en una falta de comprensión de los fundamentos de nuestra organización institucional. La idea de un poder judicial con agencia y auto percepción de agencia colectiva es diametralmente opuesta al estado de derecho.

Esta puede parecer una conclusión sorprendente, y desde luego es insensato basar una pretensión tan contraria a lo que parece ser el sentido común en esta materia en lo que adicionalmente es una interpretación un tanto forzada de un texto de Montesquieu (escrito en 1748). Pero había una razón detrás de la tesis de Montesquieu sobre la inexistencia del poder judicial en tanto tal. Y podemos claramente apreciar esa razón si conectamos el argumento hasta aquí con la caracterización de la jurisdicción defendida en este artículo.

\section{Atención al caso e independencia judicial}

Hemos visto que la jurisdicción es el poder de aplicar la ley, aplicarla en un sentido más comprehensivo que la idea peyorativa asociada con la "mera" aplicación "mecánica" de la ley. La aplicación de la que hablamos incluye el poder de adecuar las normas generales cuando éstas son, en términos de Savigny, normas de expresión impropia. Esto es algo que se aprecia atendiendo al caso particular. Por lo tanto lo que la organización del poder judicial (en el sentido propio, como una abreviatura: la organización del conjunto de jueces) debe lograr es maximizar la capacidad del juez para atender al caso. Pero ¿qué características institucionales afectan la capacidad del juez para atender al caso?

No es posible en el contexto de este artículo hacer una tipología de estas características, de modo que deberemos conformarnos con algunas apreciaciones no muy sistemáticas. Ya hemos visto algunas cuestiones que conspiran en contra de la capacidad del juez de atender al caso: el juez no puede atender propiamente al caso si está preocupado de su inestabilidad en el cargo como posible consecuencia de su decisión. Esto es el contenido más restringido de la idea de independencia judicial.

¿Qué quiere decir atender al caso? Significa atenderlo para poder decidir haciendo justicia. Ahora bien, hacer justicia al caso no es resolver el caso de acuerdo a la norma que el juez crea justa, porque no hay razón alguna para suponer que el juez podrá representar los intereses de todos los involucrados de mejor manera que el legislador. Aquí el juez estaría usando el caso como un instrumento para implementar sus creencias y la parte afectada tendría una queja legítima: “¿por qué mi caso está siendo solucionado de acuerdo a sus creencias?” El juez hace justicia al caso en la medida en que lo decide conforme a una norma justificada (legal), habiéndole prestado previamente la atención necesaria para determinar si es o no un caso típico. Y si ahora la parte formula la misma queja el juez puede responder: 
Atria- Jurisdicción e independencia judicial: El Poder Judicial como poder nulo.

"no son mis normas, son nuestras normas"30. Si la justicia es dar a cada uno lo suyo, lo "suyo" de cada parte es esta atención a la singularidad del caso.

Por eso no es compatible la atención al caso con la comprensión del caso como una oportunidad para algo distinto que resolver el caso en justicia. En particular, el caso no es una oportunidad para avanzar alguna finalidad, loable o no, del juez. Y ésta es la razón por la que la configuración institucional del poder judicial debe hacerlo en el sentido explicitado inexistente. En efecto, para garantizar la independencia judicial no basta la inamovilidad y el fuero. Es necesario dar dos pasos adicionales, que resultan naturales ahora que sabemos que la razón por la que nos importa que el juez sea independiente es que él debe estar en una posición que le permita enfrentar el caso en sus propios términos.

El primero es el que veníamos discutiendo: como no hay un agente colectivo que sea designado con la expresión "poder judicial”, el caso no puede ser entendido como una oportunidad para avanzar los intereses o aspiraciones de éste. En la medida en que existe un agente que se concibe a sí mismo como cumpliendo una función con ocasión de la cual debe actuar en un caso es prácticamente inevitable que ese agente se pregunte cómo la acción en ese caso promoverá o perjudicará la posibilidad de seguir actuando en el futuro. No se trata de que la finalidad, aspiración o iniciativa para la cual el caso es una oportunidad sea reprochable: a veces lo y otras veces no lo será. El problema no es la naturaleza reprochable o no de la finalidad, el problema es que cuando hay una finalidad para la cual el caso es concebido como un instrumento el juez pierde o se encuentra expuesto a perder la capacidad de atender a él en sus propios términos.

De nuevo, nótese la diferencia en este aspecto entre el poder legislativo y el judicial: el poder legislativo puede atender a un problema en términos instrumentales: puede creer, por ejemplo, que si resulta demasiado costoso o inconveniente requerir el pago de todos los impuestos debidos por una clase de personas se justifica una remisión parcial de las deudas tributarias, a condición de que los deudores paguen una parte de lo debido. No hay nada en principio reprochable en que el legislador actué como un agente colectivo y que, a nombre de la colectividad política, imponga a unas personas, o en ciertas circunstancias, cargas que se justifican por los beneficios obtenidos por otros, o en otras circunstancias (por supuesto, puede haber algo objetable en una situación particular de ejercicio de esta facultad legislativa, pero la objeción no será a la facultad misma sino a su ejercicio en una o varias oportunidades). El imperativo kantiano no es que las personas no deben nunca ser tratadas como medios, sino que nunca deben ser tratadas sólo como medios. El legislador no viola este imperativo al entender instrumentalmente ciertas clases de casos, precisamente porque esa ley no será aplicada por el Estado a caso alguno sin que exista la posibilidad de mirar a ese caso en términos no instrumentales.

Esta es, entonces, la razón por la que en un estado de derecho el poder judicial debe ser inexistente: en la medida en que el poder judicial se concibe a sí mismo como un agente colectivo, con intereses y demandas propias, la presión por entender el caso no en sus propios términos sino como una oportunidad para avanzar sus intereses colectivos puede ser irresistible. Si "el Poder Judicial [...] ha estado y está clamando por [...] reformas, que no

\footnotetext{
${ }^{30}$ Este punto tiene consecuencias extraordinariamente importantes para la recta comprensión del status jurídico de la constitución: véase Atria, "El derecho y la contingencia de lo político".
} 
deben seguir esperando"31, entonces el juez no podrá atender en sus propios términos al caso cuando crea que la posibilidad de que el clamor del poder judicial sea escuchado dependerá de cómo decida. De esto hemos tenido confirmación una y otra vez. Para referirme sólo a la última oportunidad de la que tengo noticia: mucho ruido se hizo de la posibilidad de que en un caso reciente el presidente de la Corte Suprema haya presionado a una ministro en visita para lograr una resolución favorable a los intereses del poder ejecutivo. Pero no hubo mayor reflexión en la posibilidad más grave, porque es más insidiosa: que no haya habido ánimo de presionar del ministro de la Corte Suprema, sino que simplemente él haya hecho que la magistrada notara lo obvio (o que la magistrada haya llegado sola a la conclusión que era obvia): que si el poder judicial está en tanto tal negociando con el poder ejecutivo para que éste escuche su "clamor", las posibilidades de que el calmor sea escuchado son mayores en la medida en que cirtas resoluciones judiciales molestas para el ejecutivo no sean dictadas. Nótese que no es necesario suponer ni prevaricación por parte de alguno de los jueces involucrados ni ejercicio abusivo de influencia por parte de los agentes de gobierno: es simplemente una consecuencia de que los jueces perciban tal cosa como los "intereses" o las "aspiraciones" del poder judicial, porque en la medida en que existan intereses y aspiraciones del poder judicial la apreciación del juez de cómo su decisión afectará la posibilidad del poder judicial de avanzarlos dificultará su atención al caso particular en tanto tal.

¿Por qué nos resulta tan común hoy en día entender al poder judicial como un agente colectivo a la par con el poder legislativo y el poder ejecutivo? ¿Cómo es que se ha convertido en un lugar común la idea de que es un defecto de nuestras instituciones el que el poder judicial no sea un "verdadero" poder del estado? Hay varias razones, pero quiero mencionar aquí sólo una ${ }^{32}$. La propia constitución exige que la Corte Suprema se pronuncie sobre proyectos de ley que afecten la organización y funcionamiento de los tribunales. ¿A qué título se pronuncia la Corte? Es difícil entender que no lo hace en representación del poder judicial. Cuando la Corte Suprema opina sobre un proyecto de ley, actúa a nombre del poder judicial. Esto está en completa oposición a los principios que subyacen a la organización de los tribunales en un estado de derecho: basta leer el art. 4 del Código Orgánico de Tribunales. Y no es raro, porque lo que los constitucionalistas llaman "el constituyente de 1980" nunca mostró demasiado aprecio por el modo occidental de entender el estado de derecho o la democracia representativa.

Ahora debemos dar el segundo paso y mirar al interior de la organización judicial para preguntarse cuáles son las condiciones en las cuales se puede esperar de un juez que atienda al caso en sus propios términos. Hoy el Poder Judicial está preocupado por la percepción negativa que de él tiene "la gente", y está haciendo esfuerzos para mejorarla. La garantía de inamovilidad del juez, la primera de las implicaciones de la idea de independencia judicial, está hoy debilitada por el uso que la Corte Suprema está haciendo de sus facultades disciplinarias. Se ha creado una comisión de ética del poder judicial que, sin forma de juicio, puede acabar con la carrera judicial de un juez sin necesidad de que éste actúe ilegalmente.

\footnotetext{
${ }^{31}$ Ministro M Garrido M, Presidente de la Corte Suprema, en su discurso de inauguración del año judicial, 1 de marzo de 2002.

${ }^{32}$ En otra oportunidad me he detenido en otra: el entusiasmo con el que la cultura jurídica chilena ha aceptado el giro vulgarista, que se explica por la errada imputación de que una de las razones por las que el poder judicial no defendió los derechos humanos durante el terror fue su formalismo. Véase Atria, "La hora del derecho. Los 'derechos humanos' entre el derecho y la política", 52-57.
} 
Atria- Jurisdicción e independencia judicial: El Poder Judicial como poder nulo.

La superintendencia de la Corte Suprema en materia jurisdiccional es desde luego requerida por nuestro argumento, pero no ocurre lo mismo con la superintendencia disciplinaria; al contrario, ella está resultando ser contraproducente. Hoy no es insensato pensar que un juez cuando falla un caso, atiende a éste preocupado de no poner en riesgo su carrera.

Así, por ejemplo, la decisión de conceder o no a un procesado la libertad provisional debe ser tomada atendiendo al caso con la finalidad de aplicar a él las reglas respectivas. El hecho de que días antes del momento en que el caso se presente para ser decidido otro procesado en libertad provisional haya cometido un delito de alto perfil periodístico debe ser irrelevante para el juez que lo decida. Pero como hoy entendemos al poder judicial como un órgano del Estado, hoy entendemos que el hecho de que ese procesado haya estado en libertad provisional es consecuencia de una decisión imputable no al juez respectivo sino al poder judicial. Es entonces el Poder Judicial el que ve afectado su prestigio por ese hecho típico. Por consiguiente cuando este otro procesado solicita su libertad provisional una de las consideraciones que el juez tendrá presente para decidirlo será la forma en que la decisión tendrá impacto en el prestigio del Poder Judicial. El caso pasa a ser (más o menos completamente) utilizado como una oportunidad para mejorar la imagen del Poder Judicial, y cada juez debe entender ahora su función no solamente en términos de atender al caso para decidirlo conforme a derecho sino adicionalmente preocupado de cómo su resolución del caso tendrá impacto en esa imagen. Por supuesto, esta consideración es probable que sea más determinante mientras más alta sea la jerarquía del juez involucrado, porque mientras más alta es la jerarquía del juez más clara aparece hoy en día la función del juez como "representante" del poder judicial (el caso extremo es la Corte Suprema, que se entiende a sí misma de tal modo en términos explícitos ${ }^{33}$ ). Por esto es importante modificar las reglas sobre superintendencia disciplinaria de la Corte Suprema: a través del ejercicio de esas facultades, la Corte Suprema puede imponer a los tribunales inferiores su concepción de cuál es la manera de cuidar el prestigio de 1 Poder Judicial. Por eso desde el punto de vista de la salvaguardia del la independencia del poder judicial (en su sentido propio: independencia de los jueces para atender al caso y así aplicar la ley), la superintendencia disciplinaria debería ser el primer ítem de la lista.

Pero por otro lado el mismo problema de que el caso se convierta en una oportunidad para avanzar o al menos no dañar la carrera del que decide surgiría si esa superintendencia se entrega a otro órgano, como a un consejo nacional de la magistratura o algo parecido. Por eso la solución correcta es a mi juicio más radical, y el tema es sensible, por lo que prefiero dejar que alguien como Piero Calamandrei la sugiera:

Se puede concluir que aun cuando la magistratura sea liberada de toda ingerencia gubernativa, no se podrá evitar que en el interior de este

\footnotetext{
${ }^{33}$ El Presidente de la Corte Suprema ha dicho, caracterizando el cargo que ocupa: "este cargo constituye un enorme compromiso, toda vez que significa estar al frente y representar un Poder del Estado al que le corresponde velar por el imperio de la ley" (Ministro M Libedinsky T, discurso de inauguración del año judicial, 1 de marzo de 2004). Asimismo la Corte Suprema en pleno y por unanimidad, al "expresar su completa disconformidad y desaliento" con la respuesta del gobierno a las propuestas de ese tribunal relativas a la autonomía funcional y financiera del Poder Judicial, objetó en particular que el gobierno sugiriera la conformación de una comisión de estudio que no la incluyera: "En efecto, se excluye a la Corte Suprema, como cabeza del Poder Judicial, del debate y análisis de los temas concernientes a la autonomía del Poder Judicial [sic]" (Acuerdo del pleno de la Corte Suprema, 12 de diciembre de 2003, Acta 111-2003).
} 
orden independiente de cualquier otro poder la independencia de cada magistrado pueda ser igualmente amenazada por el humano deseo de no enemistarse con los que pueden disponer de "su carrera" [... .] En realidad, para garantizar la independencia del magistrado y salvarlo del conformismo, el remedio ideal, al cual se aproxima el sistema inglés, consiste en la abolición de los ascensos y el reconocimiento a todos los cargos judiciales, de cualquier grado, la misma dignidad y la misma remuneración, de manera que el magistrado, una vez nombrado en un cargo judicial con base en títulos técnicos, pudiese permanecer en él para todo la vida libre del conformismo, hijo bastardo procreado por el matrimonio del temor con la esperanza ${ }^{34}$.

\section{Una objeción final y conclusión}

Contra la caracterización de la jurisdicción ofrecida en este artículo es posible imaginar la siguiente objeción: todo el peso de la especificidad de la jurisdicción recae, de acuerdo al argumento, en la posibilidad de que las normas generales sean derrotadas o, en términos de Savigny, que existan leyes de expresión impropia. Pero esto es necesariamente excepcional: los casos en que las leyes se revelan como de expresión impropia no pueden ser casos comunes, y la mayor parte del trabajo jurisdiccional debe consistir en algo distinto a corregir la impropiedad de la expresión de la ley. ¿No es insensato caracterizar la jurisdicción a partir de casos que deben ser excepcionales?

Esta objeción descansa sobre un supuesto base y una premisa intermedia. El supuesto base es que una institución o concepto no puede ser entendido desde el punto de vista de lo que desde él es excepcional. La premisa intermedia es que los casos de impropiedad de la expresión legal son en el sentido relevante excepcionales. La conclusión es que el poder de adecuar la impropiedad de la expresión legal no puede ser lo que nos provea de la clave para entender la jurisdicción, sino que debe ser algo de importancia, en el mejor de los casos, marginal.

Hay dos respuestas posibles a esta objeción: una niega su supuesto base y la otra permanece agnóstica respecto de su supuesto base pero cuestiona su premisa intermedia. Ambas son a mi juicio verdaderas, pero por razones obvias cualquiera de ellas es suficiente para responder a la objeción.

El supuesto base de esta objeción es falso porque hay buenas razones para creer precisamente lo contrario, que una institución o concepto no es entendido sino desde lo excepcional. Hay un sentido extraordinariamente importante en el cual el estudiante que no entiende los límites y las excepciones a, por ejemplo, el efecto relativo de los contratos no entiende el principio de efecto relativo de los contratos. Como sostuvo Soren Kierkegaard, aunque admitidamente en otro contexto, la excepción explica lo universal y a sí misma, y si uno realmente quiere estudiar lo universal, uno sólo necesita buscar una excepción legítima; ella devela todo mucho más claramente que el universal mismo [... . ] Si [las excepciones] no pueden ser explicadas, entonces tampoco puede ser explicado lo universal ${ }^{35}$.

\footnotetext{
${ }^{34}$ Calamandrei, Proceso y Democracia, 102.

${ }^{35}$ Kierkegaard, Repetition, 227.
} 
Atria- Jurisdicción e independencia judicial: El Poder Judicial como poder nulo.

Pero el mismo punto puede defenderse de modo menos dramático. Piénsese por ejemplo en el caso de un árbitro de fútbol. El mejor árbitro, dicen con razón los comentaristas, es el que menos se nota. Un árbitro de fútbol en principio no debería necesitar intervenir en el juego, porque las infracciones a las reglas son excepcionales en exactamente el mismo sentido conceptual en que los casos de leyes de expresión impropia lo son: no pueden ser concebidas como la norma general, porque en ese caso estaríamos jugando otro juego, no fútbol. Pero el hecho de que las infracciones a las reglas no puedan ser entendidas sino como excepciones en el contexto de la práctica del fútbol no quiere decir que no podamos definir la función del árbitro como quien está a cargo de declarar con autoridad que los hechos operativos de una regla del fútbol se han realizado y que en consecuencia una posición institucional ha sido creada, modificada o extinguida ${ }^{36}$.

Pero aún aceptando el supuesto base de la objeción es posible responderla, y esta respuesta es importante porque nos lleva al núcleo de lo que debe caracterizar a cualquier versión aceptable actualmente de positivismo jurídico (es decir, cualquier positivismo ético ${ }^{3}$ ). Como hemos visto, la idea de aplicación mecánica de la ley que es injustamente asociada con Montesquieu es inaceptable porque supone que el caso particular que sea sometido al juez será resuelto sin atender a él; el caso en tanto tal no sería visible para el juez, que sólo vería un conjunto de propiedades que de acuerdo a la formulación literal de las normas del sistema son relevantes. Pero el juez no podría enfrentar al caso en tanto caso singular, y de este modo no podría tratar con justicia a las partes del caso. Al contrario, el juez trataría el caso como la oportunidad para aplicar reglas generales. Pero esto es tratar a las partes como instrumentos, como medios para conseguir el fin legislativo. La caracterización de la jurisdicción ofrecida en este artículo supera este problema. El argumento central es la distinción entre modificar una norma y corregir la impropiedad de su expresión. El juez que modifica una norma está actuando no como juez sino como activista disfrazado de juez; el juez que corrige la impropiedad de su expresión está siendo fiel a la ley. En términos cuantitativos la objeción es correcta, porque los casos de impropiedad de expresión deben ser y permanecer excepcionales. Pero en términos normativos, desde el punto de vista de la legitimidad de la autoridad reclamada por el juez y del tipo de comunidad política de la cual el derecho es expresión, la cuestión no es marginal. La distinción entre modificar una norma y corregir la impropiedad de su expresión permite distinguir entre usar casos (y a las personas envueltas en ellos) como medios y atender a ellos en sus propios términos.

Hoy está de moda devaluar la autoridad del legislador y sobrevalorar la autonomía del juez. No hay en esto nada novedoso. Esto es un retroceso a formas premodernas de comprensión del derecho, en el cual éste no era creado por los ciudadanos (que entonces eran súbditos) sino descubierto a través del ejercicio de la razón entrenada de jueces y

\footnotetext{
36 Antes de continuar, y para prevenir malos entendidos: no estoy diciendo que la función del juez sea análoga a la del árbitro. El punto no es sobre la similitud entre la función jurisdiccional y la del árbitro de fútbol, una analogía que ha sido fuente de una enorme cantidad de confusiones en la teoría del derecho (véase el capítulo 1 de Atria, Law and Legal Reasoning). Lo único que estoy intentando clarificar aquí es que del hecho de que una situación deba ser, en el contexto de una práctica, entendida como excepcional no se sigue que no pueda o deba ser utilizada para caracterizar una función que no debe ser entendida como excepcional.

37 Sobre la explicación de lo que entiendo por positivismo ético y por qué cualquier versión aceptable del positivismo jurídico debe recibir esta descripción, véase Atria, "La ironía del positivismo jurídico".
} 
REJ - Revista de Estudios de la Justicia - No 5 - Año 2004

abogados. El derecho moderno, fundado en la idea de voluntad soberana a la que hace referencia el artículo $1^{\circ}$ del Código Civil, hace posible la transformación de súbditos en ciudadanos que se autogobiernan. Hoy es común oír que esta visión reduce la función judicial a la aplicación mecánica de la ley. He tratado de mostrar que esto es falso. La idea de que el juez media entre la universalidad de la ley, que nos hemos dictado en ejercicio de nuestra facultad de autogobierno, y el caso particular al cual esa ley ha de ser aplicado, único e irrepetible, esa idea contiene la promesa más admirable del derecho: que podemos gobernarnos a nosotros mismos y al mismo tiempo tratarnos como fines, no como medios.

\section{Referencias}

Atria, F: "Las circunstancias de la derrotabilidad", en 45 Revista de Ciencias Sociales (2000): 437-467.

On Law and Legal Reasoning (Oxford: Hart Publishers, 2002).

“La hora del derecho. Los 'derechos humanos' entre el derecho y la política”, en 91 Estudios Públicos (2003): 45-90.

"El derecho y la contingencia de lo político", en 26 DOXA (2004): 319-345.

“La ironía del positivismo jurídico", en 27 Doxa (2005, de próxima aparición): 79-119.

Atria, F, E Bulygin, J J Moreso, P Navarro, J L Rodríguez y J Ruiz Manero: Lagunas del Derecho (Madrid: Marcial Pons, 2005, en prensa).

Bascuñán, A: "Delitos contra intereses patrimoniales", en 1 Revista de Derecho de la Universidad Adolfo Ibáñez (2004).

Constant, B: Curso de Política Constitucional (Madrid: Taurus, 1968).

Correa, R: "Tribunal Constitucional”, en 1 Revista de Derecho de la Universidad Adolfo Ibáñez. (2004), pp. 481-550.

Detmold, M J: “Law as practical reason", en 48 Cambridge Law Journal (1989): 436-471.

Günther, K: The Sense of Appropriateness (Albany: SUNY, 1993).

Habermas, J: Facticidady Validez (Madrid: Trotta, 1998; ed. original 1992).

Hart, H L A: "Problems of the philosophy of law", en Hart: Essays in Jurisprudence and Philosophy (Oxford: Clarendon Press, 1967), pp. 88-120.

Kant, I: "Sobre un presunto derecho de mentir por filantropía" (1797), en I Kant: Teoría y Práctica (Madrid: Tecnos, 1986), pp. 61-68.

Kelsen, H: Teoría Pura del Derecho (1960), in 1960 (México: Porrúa, 1991; ed. original 1960).

Kierkegaard, S: Repetition, in Fear and Trembling and Repetition (Princeton: Princeton University Press, 1983 ; ed. original 1843).

Montesquieu: Del Espiritu de las Leyes (Madrid: Tecnos, 1995; ed. original 1748).

Rawls, J: "Dos conceptos de regla", en P Foot (ed): Teorías sobre la Ética (México: Fondo de Cultura Económica, 1955), pp. 210-247.

Searle, J: Actos de Habla (Madrid: Cátedra, 1986).

Von Savigny, F: Sistema del Derecho romano Actual (Madrid: F Góngora y Compañía editores, 1878; ed. original 1840).

Weber, M: Economy and Society (Berkeley: University of California Press, 1978; ed. original 1922). 